\title{
The Insurgence of Tramadol Abuse among the Most Active Population in Jirapa Municipality: A Study to Assess the Magnitude of the Abuse and Its Contributory Factors
}

\author{
Ferguson Saapiire $\mathbb{D}^{1},{ }^{1}$ Godfrey Namillah, ${ }^{1}$ Vincent Tanye $\mathbb{D}^{1},{ }^{1}$ and Abdulai Abubakari ${ }^{2}$ \\ ${ }^{1}$ St. Joseph Nursing Training College, Ministry of Health, P.O. Box 24, Jirapa, Wa, Ghana \\ ${ }^{2}$ Department of Public Health, School of Allied Health Sciences, University for Development Studies, P.O. Box 1883, Tamale, Ghana \\ Correspondence should be addressed to Ferguson Saapiire; saapiireferguson@yahoo.com
}

Received 24 May 2020; Revised 27 July 2020; Accepted 13 January 2021; Published 8 February 2021

Academic Editor: James Grutsch

Copyright (c) 2021 Ferguson Saapiire et al. This is an open access article distributed under the Creative Commons Attribution License, which permits unrestricted use, distribution, and reproduction in any medium, provided the original work is properly cited.

\begin{abstract}
Background. Tramadol has gained popularity among the drugs of the most active population especially the respondents in Ghana abuse especially farmers who nicknamed as "farm and buy cow." It has recently become a public health concern, and stakeholders are worried about tramadol abuse and its implications on health in the Upper West Region. The study sought to measure the prevalence of tramadol/related substance abuse and the associated factors. Methods. A community-based analytic cross-sectional study involving 420 respondents was conducted. The participants were selected using a multistage sampling technique. Semistructured questionnaire was used to generate the data. Results. About $77.6 \%$ of the respondents abuse tramadol while $83.9 \%$ of the participants take at least one other related substance or drug. Participants with history of any substance abuse were 5 times more likely to abuse tramadol $[\mathrm{AOR}=5.15 ; 95 \% \mathrm{CI}(1.501-17.656) ; p=0.009$ ], compared to respondents with no history of any substance abuse. Respondents who take tramadol to enhance sex were 4 times more likely to abuse tramadol $[\mathrm{AOR}=3.776 ; 95 \%$ CI $(1.352-10.545) ; p=0.011]$. Formal sector employment was protective against tramadol abuse $[\mathrm{AOR}=0.100 ; 95 \% \mathrm{CI}(0.017-0.595) ; p=0.011]$ compared to self-employment and the unemployed. In addition, use of nonopioid prescription drugs for posttraumatic/pain management reduced the risk of tramadol abuse $[\mathrm{AOR}=0.237 ; 95 \% \mathrm{CI}$ (0088-0.640); $p=0.004]$ compared to the posttraumatic/pain management dependence on prescription of only opioid like tramadol. Conclusion. An infantile municipality like Jirapa is challenged with high level of tramadol and related substance which has serious repercussion on the health system in the Jirapa district. It is important that measures are taken by the stakeholders to stop tramadol and related substance and mitigate the impact of drug abuse in the district.
\end{abstract}

\section{Background}

The world is in opioid crisis; in fact, prescription drug abuse has monumentally increased; cocaine and opium absolutely hitting the highest records in the history of the world presenting multiple challenges on multiple fronts [1]. The extent of nonmedical use of prescription-only drugs is becoming a major threat to global public health and law enforcement worldwide. Off late, opioids have been identified to cause more harm to the world population and have accounted for $76 \%$ of deaths where drug use disorders were implicated worldwide in 2018 [1]. The new phenomenon that has been detected is that opioid use is booming as tramadol crisis emerges in Africa [2]. It is one of the most widely used drugs in several West African countries for nonmedical purposes after cannabis, which remains by far the most popular globally. Tramadol is a synthetic 4-phenyl piperidine analogue of codeine, centrally acting analgesic with strong opioid agonist properties as well as inhibitory effects on the reuptake of noradrenaline and serotonin [3]. It was initially thought to have minimal addictive potentials when compared to other opioid analgesics, but the unfolding scenarios are contrary. Drug abuse is the indiscriminate use of drugs without a doctor's prescription. This definition covers everything that 
people ingest, inhale, or absorb. It includes medicines, overthe-counter drugs, illegal drugs, beverages, cigarette, food additives, industrial chemicals, and even food. Drug abuse is taking of drugs to the extent that they cause social or medical harm to the take [4]. Reasons advance for drug abuse are peer group influence, psychological or physiological factors, environmental factors, unemployment, unmet expectations, and media advertisement [5]. The consequences of drug abuse include mental illness, liver and kidney-related diseases, low productivity, child abuse, sexual abuse, loss of individual integrity, financial mismanagement, destruction of family hope, and untimely death [6].

The current trend of substance abuse among women is a major national concern. It has detrimental effects on women's health and behavior and could lead to death [1].

The extent of abuse of tramadol and codeine among pupils at both basic and junior high schools in the Upper West Region is alarming [7]. It is true that tramadol has gained notoriety among the drugs that the respondents widely abused in the region [8]. No wonder some farmers in the localities have nicknamed it with the name "Koo da nan hum" literally meaning farm and buy cow [9]. Research found that students take the drug to exert their strength when having sexual intercourse with their partners while others take it just for pleasure [9]. While health workers, parents, food and drug regulators, civil society organizations, and the security agencies are all worried about the abuse of tramadol in the region, it is shown that there are even other dangerous substances which are more hazardous than tramadol that people in the district indulge in [9]. The current state of tramadol abuse is not only a threat to public health of the municipality but also a recipe for social vices or the falling standards of morality and education in the municipality. Regardless of the level of pervasiveness of the abuse, documented evidences are not available to justify the situation in the municipality. The study therefore is aimed at assessing the prevalence of the tramadol abuse and associated factors.

Tramadol is sometimes abused alongside other drugs, which is called polydrug use. Typically, users combine tramadol with other substances to increase their high or selfmedicate. The following drugs are commonly combined with tramadol: alcohol, other painkillers, sedatives, like benzodiazepines and sleeping pills, and cold medicine [10].

\section{Methods}

2.1. Study Area. The study was conducted specifically in the Jirapa Municipality of the Upper West Region with a territorial size of $1,188.6$ square kilometers. The municipality is divided into submunicipals for effective health services delivery purpose. There are seven (7) submunicipals administratively managed by Submunicipal Health Teams (SMHTs). The study took place in Hain, Tizza, Duori, Tuggo, Yaga, Sabuli, and Jirapa urban submunicipals. In 2017, the entire population of the municipality is estimated to be 101,899 . The LI 1902 established Jirapa District which was carved out of the then Jirapa-Lambussie District in light of Ghana's decentralization processes in 2007 and was upgraded into a municipal status in 2018 .
2.2. Study Design and Target Population. The study was an analytical community-based cross-sectional design involving the most active population within the ages $15-55$ years. All persons below 15 years and above 55 years were excluded. All critical ill-patient was equally excluded. Persons who currently abuse/misuse tramadol were included in the study.

2.3. Sample Size and Sampling. Sample size was estimated using the Cochran's formula for quantitative continuous data. In addition to the $10 \%$ nonresponder rate, a sample size of 420 persons was used for the study. A prevalence of $50 \%$ was used for the estimation of the sample size with an acceptable margin of error of 5\%. The respondents were selected across the seven submunicipals for the study.

A multistage sampling procedure was used for the study. Stratified sampling was used to stratify the seven submunicipals into stratums. Simple random sampling procedure was used to select the communities within each stratum for the study. This was randomly done using the ENA sampling software. A comprehensive list of all households that constituted the sample frame was compiled from a chosen cluster, and systematic sampling technique was used to select the study households. The first household was selected using the table of random numbers. In the selection of the study participants, only one eligible respondent was selected using a simple random sampling technique in a household.

2.4. Data Collection Methods. A semistructured questionnaire made of both open and closed-ended questions was used to collect the data from the respondents. The questionnaires were personally administered in a face-to-face interview by research assistants. The tool was to enable us to collect both qualitative and quantitative data. In addition, it enables us to collect large range of different responses from respondents. Also, the choice was made for purposes of data triangulation of responses. The questionnaire was the main instrument used for the collection of data. There were some open-ended questions as well as closed or multichoice questions. The open-ended questions provided in-depth understanding into some of the reasons underpinning the use of tramadol and other abusive substances. Face to face interview was administered because other modes (telephone and social media) would have been problematic because abusers of tramadol would have been suspicious as it is illegal to take it in Ghana.

Ample time were given to the respondents to study the pattern of the instruments and to answer appropriately without being rushed. Respondents' preferred choices were ticked. However, in instances where respondents cannot read and write, the data collector read out to the respondent in a language (Dagaare) that he/she understood. Piloting of the questionnaire was done a day after the practical training sessions of the enumerators. The team reconvened to discuss thoroughly about the entire exercise, and some misconceptions, flexibility issues of the data collection tool, and interpretations were further clarified. Also, the validity and reliability tests were ran to determine precision level of the tool. The determination was based on Cronbach's alpha. 
TABLE 1: Demographic characteristics.

\begin{tabular}{|c|c|c|c|}
\hline Characteristics & Mean age $(x \pm s)$ & Frequency $(n=420)$ & Percent $(\%=100)$ \\
\hline Age & $28.3 \pm 7.87$ & & \\
\hline$<18$ yrs & & 9 & 2.1 \\
\hline $18-25$ yrs & & 171 & 40.7 \\
\hline $26-30 \mathrm{yrs}$ & & 113 & 26.9 \\
\hline 30 yrs- -55 yrs & & 127 & 30.3 \\
\hline \multicolumn{4}{|l|}{ Educational level } \\
\hline No education & & 86 & 20.5 \\
\hline Basic level & & 143 & 34.0 \\
\hline At least 2 nd cycle & & 191 & 45.5 \\
\hline \multicolumn{4}{|l|}{ Marital status } \\
\hline Single & & 224 & 53.3 \\
\hline Married & & 196 & 46.7 \\
\hline \multicolumn{4}{|l|}{ Occupation } \\
\hline Unemployed & & 165 & 39.3 \\
\hline Agric/galamsey & & 114 & 27.1 \\
\hline Artisans/hairdresser/seamstress/traders etc. & & 110 & 26.2 \\
\hline Govt worker & & 31 & 7.4 \\
\hline \multicolumn{4}{|l|}{ Sex } \\
\hline Male & & 342 & 81.4 \\
\hline Female & & 78 & 18.6 \\
\hline \multicolumn{4}{|l|}{ Religion } \\
\hline Christian & & 284 & 67.6 \\
\hline Moslem & & 75 & 17.9 \\
\hline Traditionalist & & 61 & 14.5 \\
\hline
\end{tabular}

Some closed-ended questions were modified, and some were deleted until $R=0.8$.

Data on sociodemographic and economic variables (gender, religion, occupation, education, and marital status), peer pressure, weak enforcement of regulations, posttraumatic/management dependence, curiosity, psychological/mental health challenges, and ignorance were collected. Also, data on the knowledge of respondents on the effects of tramadol abuse, the perceptions of the study population on the associated benefits of tramadol use, and the abuse of other related substances/drug were taken. In addition, data on other variables like awareness of the availability of the drugs, taking the drug with or without medical officer approval, duration, and dosages of tramadol mostly patronized were collected. A rating scale was used to assess the level of perception on the benefits associated with tramadol use and the knowledge on the consequences of tramadol abuse. The rating scale sought to ascertain the degree of acceptance or rejection to some parameters associated or related with tramadol among the study group. A scale of agree, strongly agree, do not know, disagree, and strongly disagree was used for the assessment.

2.5. Data Analysis. Statistical Package for the Social Sciences (SPSS) Version 21(SSPS Inc. Chicago, IL, USA) was used for the data entry, cleaning, and analysis. Missing data and wrong entries were checked, and all irregularities were cor- rected. The abuse/misuse of the tramadol by this study was defined as inappropriate use of the drug or use of the drug without physician's approval. The approved tramadol dosage strengths for use in Ghana by the FDA are $50 \mathrm{mg}$ and $100 \mathrm{mg}$ in tablets and capsules and $50 \mathrm{mg} / \mathrm{ml}-2 \mathrm{ml}$ in injections, and therefore any intake above these strengths were considered as abuse.

Results from the rating scale assessment were statistically transformed into dichotomous variables of yes/no. Agree and strongly agree were considered as accepted (yes) while disagree and strongly disagree were considered as rejection (no) to a particular parameter. Knowledge on the effects/consequences of tramadol was a composite indicator of the study participants who have the knowledge that its abuse/misuse has an effect on a person and the number of the study group who are knowledgeable that the abuse/misuse of the tramadol can lead to mental problems including depression, insomnia, and addiction, while the knowledge on the consequences of tramadol abuse was classified as low or high. In addition, the perception of the respondents on the benefits associated with the abuse/misuse of tramadol was categorized as having low or high perception on the benefits. It was also a composite indicator. Tramadol abuse was the main dependent variable.

Descriptive statistics were generated from the data. Chisquare test was used for the bivariate analysis to establish the relationship between tramadol abuse and independent 
TABle 2: Prevalence of tramadol misuse/abuse.

\begin{tabular}{|c|c|c|c|}
\hline Characteristics & Frequency $(N=420)$ & Percent (\%) & $(x \pm s)$ \\
\hline Aware of tramadol & 402 & 95.7 & \\
\hline Seen tramadol & 280 & 66.7 & \\
\hline Tramadol use & 152 & 36.2 & \\
\hline Used tramadol without physician approval/inappropriate use & 118 & 77.6 & \\
\hline \multicolumn{4}{|l|}{ Duration of tramadol usage } \\
\hline$<1$ month & 17 & 11.2 & \\
\hline Less than $1 \mathrm{yr}$ & 32 & 21.1 & \\
\hline $1-5 \mathrm{yrs}$ & 79 & 52.0 & \\
\hline $5-10$ yrs & 24 & 15.7 & \\
\hline \multicolumn{4}{|l|}{ \# of capsule/tablet taken daily } \\
\hline One & 26 & 17.1 & \\
\hline Two & 72 & 47.4 & \\
\hline Three & 28 & 18.4 & \\
\hline At least four & 26 & 17.1 & \\
\hline Mean milligram daily intake $(x \pm s)$ & & & $100 \pm 42.6$ \\
\hline \multicolumn{4}{|l|}{ Milligram taking on daily } \\
\hline $50 \mathrm{mg}$ & 28 & 18.4 & \\
\hline $100 \mathrm{mg}$ & 46 & 30.3 & \\
\hline $125 \mathrm{mg}$ & 18 & 11.8 & \\
\hline $200 \mathrm{mg}$ & 10 & 6.6 & \\
\hline Do not know & 50 & 32.9 & \\
\hline \multicolumn{4}{|l|}{ Know a person sick/mentally challenge due to tramadol abuse } \\
\hline No & 347 & 85.5 & \\
\hline Yes & 59 & 14.5 & \\
\hline
\end{tabular}

variables. A relationship was considered significant when $p$ $<0.5$. Multivariate analysis was done to control for confounders and to exactly identify determinants/predictors of the tramadol abuse among the study population by using logistic regression analysis. All the independent variables that proved statistically significant $(p<\alpha$ value) at the bivariate level were put for multivariate analysis. Socioeconomic and demographic variables (sex, religion, employment status, and educational level), knowledge on the consequences of tramadol abuse (level of knowledge on consequences, know whether tramadol abuse has an adverse effect, and know whether tramadol abuse leads to mental problems), perceptions on benefits of tramadol (level of perception on benefits, sex enhancer, and good euphoria), and other variables (reasons for the use of the drug, abuse of other related substances, posttraumatic/management dependence, and know a person abusing the drug) with $p$ values less than 0.05 were considered for the modeling.

\section{Results}

3.1. Socioeconomic and Demographic Characteristics. The mean age of the study participants was $28.3 \pm 7$ years. Most of the study participants $(40.7 \%)$ were found in the age group 18-25years. About $81.4 \%$ of the respondents were males. Majority of the respondents (specify the figure) were selfemployed. Most participants 191 (45.5\%) had at least second- ary education. About $46.7 \%$ of the participants were married whereas the majority (53.3) were single. Again, most participants (67.6\%) were Christians (Table 1).

3.2. Prevalence of Tramadol Misuse/Abuse. The prevalence of tramadol use is $36.2 \%$ among respondents in the municipality with $77.6 \%$ of the users inappropriately taking or misusing/abusing the drug. Averagely, the daily milligram intake of tramadol was $100 \mathrm{mg} \pm 42.6 \mathrm{mg}$. About $32.9 \%$ of the participants misuse tramadol without knowing the various strength/dosages they take. Regardless of the strength, $17.1 \%$ of the study participants can take at least 4 tablets/capsules at once. The vast majority of the respondents patronize dosages $\geq 100 \mathrm{mg}$ (Table 2 ).

3.3. Reasons for the Intake/Misuse of Tramadol. The first three commonest reasons why majority of respondents took tramadol were peer influence $(38.8 \%)$, improve physical performance $(37.5 \%)$, and improve physical strength/become more active $(24.3 \%)$.

Summary of the reasons indicate that majority (54.6\%) took the drug to solve a single challenge while $29 \%$ use the drugs for multiple reasons. However, a significant number has no reason for the use of the drug (Table 3). The influenced by friends was the most reason $(34.9 \%)$ for the firsttime tramadol use and the continuous use/misuse while 
TABLE 3: Reasons for the intake/misuse of tramadol.

\begin{tabular}{|c|c|c|}
\hline Reasons & $\begin{array}{l}\text { Number of users } \\
(N)\end{array}$ & $\begin{array}{l}\text { Percent } \\
(\%)\end{array}$ \\
\hline \multicolumn{3}{|c|}{ Reasons for the current use of tramadol } \\
\hline $\begin{array}{l}\text { Took tramadol because of } \\
\text { sickness }\end{array}$ & 28 & 18.4 \\
\hline $\begin{array}{l}\text { To do more hard/physical } \\
\text { work }\end{array}$ & 57 & 37.5 \\
\hline To enhance sleep & 12 & 7.9 \\
\hline To look strong and young & 37 & 24.3 \\
\hline No reason & 18 & 11.8 \\
\hline I do not know & 5 & 3.3 \\
\hline To enhance sex & 13 & 8.6 \\
\hline To release stress & 26 & 17.1 \\
\hline $\begin{array}{l}\text { Involved in road traffic } \\
\text { accident }\end{array}$ & 8 & 5.3 \\
\hline Parents or relative offer & 11 & 7.2 \\
\hline Friends encouraged me & 59 & 38.8 \\
\hline To get away from my problems & 21 & 13.8 \\
\hline To get high (good euphoria) & 22 & 14.5 \\
\hline $\begin{array}{l}\text { Prescription given by a } \\
\text { physician }\end{array}$ & 23 & 15.1 \\
\hline \multicolumn{3}{|c|}{ Summary of reasons of the use of drugs } \\
\hline $\begin{array}{l}\text { No reason at all for the use of } \\
\text { drug }\end{array}$ & 25 & 16.4 \\
\hline Single reason & 83 & 54.6 \\
\hline Multiple reasons & 44 & 29.0 \\
\hline
\end{tabular}

$19.1 \%$ of the first-time users said they took tramadol because of curiosity (Figure 1).

3.4. Sources of Tramadol in the Jirapa Municipality. Also, about $95.7 \%$ of the study participants were aware of the existence of tramadol in the municipality. Majority $(81.5 \%)$ of the participants voted "yes" for licensed chemical shops as the main and reliable source of tramadol. Not surprising, almost $61.1 \%$ of the respondents took drug peddlers as the second most reliable source, whereas $36.7 \%$ of respondents voted "yes" for black markets as the third reliable source of tramadol for the respondents (Table 4). The remaining $22.2 \%$ and $17.3 \%$ of respondents voted for hospital and moving vans, respectively.

3.5. Prevalence of Other Substances Abuse by the Respondents in the Municipality. About $64.5 \%$ abuse alcohol, and almost half of the respondents inhale substances popularly known as sera or Enye or snuff. Also, $17.9 \%$ and $6.4 \%$ were found abusing prohibited substances like cocaine/heroine and wee/marijuana, respectively. Interestingly, quite a number of respondents were engaged in abusing emerging substances such as "Wuole" (17.1\%), sniffing glue (6.2\%), inhaling petrol/turpentine (1.9\%), and drinking of soaked/boiled diapers/pads (1.4\%) (Table 5).

About $38 \%$ and $34 \%$ of the abusers attained at least secondary education and basic education, respectively. The remaining $28.8 \%$ had no formal education (Table 6). A positive association $(p=0.046)$ was observed between the educational status of the participants and abuse of tramadol. Compared to the unemployed (39.9\%) and respondents engaged in formal employment (2.5\%), majority (57.6\%) of abusers were self-employed. However, the employment status of the respondents was significantly associated with tramadol abuse $(p=0.003)$. A statistically significant positive association also was observed between religion and tramadol abuse. In spite of this, about $59.4 \%$ of the abusers were Christian. Finally, it was gender/sex showed a strong positive association with tramadol abuse $(p=0.009)$.

A higher proportion (63.2\%) of the respondents believed that there are extraordinary benefits associated with abusing tramadol. Therefore, the perception of respondents on the benefits of tramadol use was significantly related to its abuse $(p=0.027)$. Also, taking tramadol for purposes of enhancing sexual performance/prolongation of the time of intercourse $(p=0.001)$ and taking tramadol to improve on euphoria/pleasurable effect $(p=0.046)$ were statistically significantly associated with tramadol abuse. It was observed that quite majority $(65.1 \%)$ did not have adequate knowledge on the dangers/consequences associated with tramadol abuse. However, there was a positive association $(p=0.009)$ between tramadol abuse and the knowledge index on dangers.

Furthermore, approximately $89.5 \%$ of the respondents took the drug to relieve pain. In addition, knowledge of a person taking tramadol without a physician prescription was associated with a person abusing tramadol $(p=0.001)$. It was noted that almost $74.3 \%$ of the tramadol users have a friend or a relative abusing tramadol. Though a few $(38.2 \%)$ assented to role of posttraumatic/pain management dependence in tramadol abuse, a positive association was observed between them $(p=0.044)$. A lot of $(77.6 \%)$ of the respondents were involved in other related substance abuse. A positive significant association was also observed between history of other substance abuse and tramadol abuse $(p=0.001)$ which were relatively linked to tramadol abuse. Close to $78.9 \%$ have justified reasons for the abuse of tramadol (Table 7).

3.6. Determinants of Tramadol Abuse among the Most Active Population. The results of the logistic regression revealed that the occupation status, abusing tramadol for purposes of sexual enhancement, a history of other substance abuse, and posttraumatic/pain management dependence were statistically significantly associated with the abuse of tramadol.

This set of variables accounted for $30.5 \%$ of the variability of abuse/misuse of tramadol (Nagelkerke $R$ Square $=0.305$ ). Compared to respondents with no history of any substance/drugs abuse, respondents with history of any substance abuse were 5 times more likely to be engaged in the misuse/abuse of tramadol $[\mathrm{AOR}=5.15 ; 95 \%$ CI (1.501-17.656); $p=0.009$ ]. The odds of abusing tramadol for purposes of sexual enhancement was higher among respondents. Compared to respondents who rejected the perception that tramadol was a sex enhancer, the respondents who take tramadol to enhance sex were 4 times more likely to take tramadol without physician prescription/inappropriately engaged in taking 

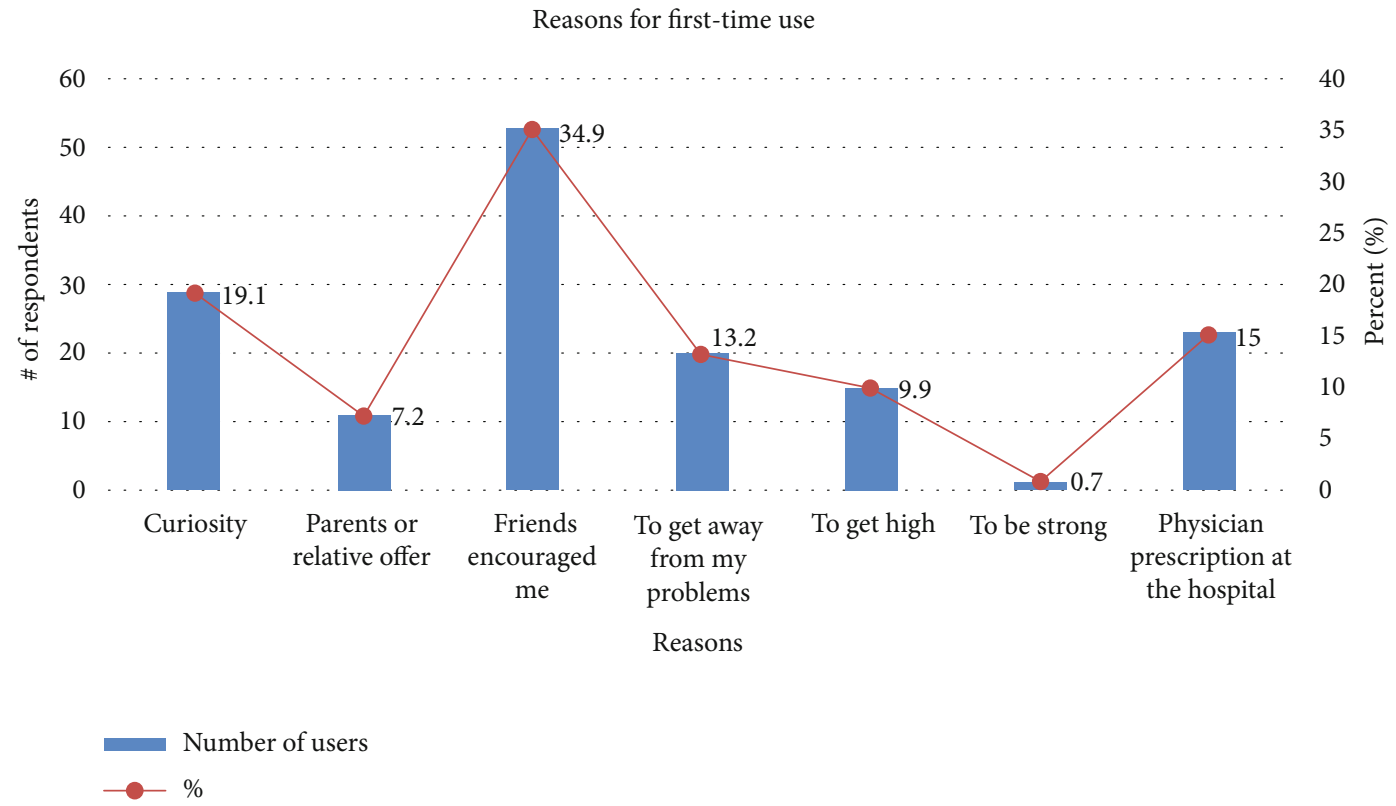

Figure 1: Purpose for the intake of tramadol for the first time.

tramadol $[\mathrm{AOR}=3.776 ; 95 \%$ CI $(1.352-10.545) ; p=0.011]$. The odds of respondents abusing tramadol was significantly higher among unemployed respondents [AOR $=0.100 ; 95 \%$ CI (0.017-0.595); $p=0.011]$ compared to respondents who were engaged in government work or self-employed. Comparatively, there is an increased risk of $23.7 \%$ of the respondents likely to continuously depend on opioid prescriptiononly drugs like tramadol after been used to manage trauma or pain-related illness in the hospital $[\mathrm{AOR}=0.237 ; 95 \% \mathrm{CI}$ (0088-0.640); $p=0.004$ ].

The rest of the independent contributory variables were statistically not significant $(p \geq 0.05)$ and were removed by hideout from the model during the modeling process (Table 8).

\section{Discussion}

4.1. Prevalence of Tramadol Abuse, Clinical and Drug Related Parameters and Other Related Substance Abuse. The current study identified that $402(95.9 \%)$ and 280 (66.7\%) of the respondents had heard and saw tramadol, respectively. Out of this number 152 (36.9\%) and 118 (77.6) had individually used and abused/misused tramadol. Elhabiby in his systematic analysis found similar findings especially in many African countries [11]. For example, a prevalence of $64 \%$ abuse of tramadol was reported in Nigeria, which was consistent with the findings of the present study [11]. In the united State of America, the number of tramadol abuse or misuse increased approximately $250 \%$ from 2005 to 2011 among visitors of the emergency department [12]. The World Health Organization (WHO) warned the growing evidence of tramadol abuse in many African and West Asian countries despite the challenge of large seizures of such preparations in North and West Africa [13]. Also, a study by Elliason et al. made the same revelation about the level of awareness and knowledge of the respondents on the availability of tramadol [8].

The abuse of substances and other drugs in the municipality is alarming as unearthed by the study. The emergence of new forms of abuses puts the municipality at risk of public health disasters and rising trends of social vices. The called by the District Director of Health Services of Sunyani West district in the Brong-Ahafo region of Ghana reaffirmed the findings of the current study about the looming danger of abuse of "Wuole" (a mixture of akpeteshie or other jin and wee or cocaine with or without ginger) in Ghana [14]. About $6.2 \%$ of the respondents were found sniffing glue despite the adverse consequences associated with it. This abuse is widespread across the world. A study in the USA has reported that nearly $20 \%$ of adolescents have experimented with illicit drugs. Sniffing among other inhalants constitutes the first drugs that are being experimented by the adolescents [15]. Also, other emerging substances like drinking of soaked/boiled diapers/pads, inhaling of petrol/turpentine, and smoking of dried faeces and nim tree in the municipality are of a big worrisome situation. The surge of this new phenomenon seems to catch the eyes of most West African leaders [16].

On high prevalence of substance abuse, almost half the respondents were found abusing alcohol, Indian herm or wee, mahogany/bitter roots with alcohol/akpeteshie, and "sera" or "Enye." In this regard, the findings of the following studies are consistent with findings of the current study [1720]. The high patronage of sera or snuff revealed by the current study is alarming with regard to the number of respondents involved. However, findings of studies in Ghana [8, 21] are in consonance with the $45 \%$ prevalence of the respondents abusing snuff/sera as found in the present study.

4.2. Demographic and Socioeconomic Variables and Tramadol Abuse. The present study established that gender, 
TABLE 4: Sources of tramadol.

\begin{tabular}{lcc}
\hline Sources & $\begin{array}{c}\text { \# of participants of the study who agreed to } \\
\text { the following sources of tramadol }\end{array}$ & $\%$ \\
\hline $\begin{array}{l}\text { Licensed } \\
\text { chemical }\end{array}$ & 331 & 81.5 \\
dealers & & \\
Drug peddlers & 248 & 61.1 \\
Black markets & 149 & 36.7 \\
Hospital & 90 & 22.2 \\
Moving vans & 70 & 17.3 \\
\hline
\end{tabular}

TABle 5: Prevalence of other substance abuse.

\begin{tabular}{lcc}
\hline Substance & $\begin{array}{c}\text { \# of abusers } N= \\
420\end{array}$ & $\begin{array}{c}\text { Percent } \\
(\%)\end{array}$ \\
\hline Cocaine/heroine & 27 & 6.4 \\
Smoking of wee/marijuana & 75 & 17.9 \\
Alcohol abuse & 271 & 64.5 \\
Sniffing of snuff ("sera"/"Enye") & 189 & 45.0 \\
Intake of "Wuole" & 72 & 17.1 \\
Smoking of nim tree & 27 & 6.4 \\
Intake of mahogany roots with & 132 & 31.4 \\
alcohol & & \\
Drinking of soaked/boiled & 6 & 1.4 \\
diapers/pads & 8 & 1.9 \\
Inhaling of petrol/turpentine & 11 & 2.6 \\
Smoking of dried faeces & 26 & 6.2 \\
Sniffing glue & &
\end{tabular}

"Wuole" *(mixture of boiled wee and akpeteshie or local jin and with/without ginger).

religion, education status, and employment status were significantly related with the abuse of tramadol. A case study of tramadol use in Lagos state, Nigeria, established the relationship between socioeconomics, demographic characteristics, and tramadol abuse which is in support of the findings of the current study [22]. Similarly, Wassa Amenfi West Municipality study also confirmed such relationship [8]. Also, a KAP (knowledge, attitude, and practice) study by Mohammed et al. in Gaza among clients patronizing private psychiatric clinics also observed an association between socioeconomic factors and tramadol abuse [23]. A study in north-eastern Nigeria found over $93 \%$ of tramadol users being males [24]. Also, education level, gender, knowing a parson abusing the drug, and history of smoking were found related with tramadol abuse by a study in Iran which is consistent with the findings of the present study [25].

4.3. Perceptions on the Benefits of Tramadol, Other Reasons and Abuse/Misuse of Tramadol. The present study found that having low or high perception on the benefits of tramadol influences the abuse of the drug. The perception that the use of tramadol is a sexual enhancer and improves euphoria was significantly related with tramadol abuse. Ghana drugs report in 2019 noted that tramadol can induce a sense of
TABLE 6: Sociodemographic characteristics associated with tramadol abuse.

\begin{tabular}{|c|c|c|}
\hline $\begin{array}{l}\text { Demo-socioeconomic } \\
\text { characteristics }\end{array}$ & $\begin{array}{c}\text { Misusers/abusers of } \\
\text { tramadol } \\
N(\%)=118\end{array}$ & $\begin{array}{c}p \\
\text { value }\end{array}$ \\
\hline \multicolumn{3}{|l|}{ Sex } \\
\hline Male & $107(90.7)$ & \multirow{2}{*}{0.009} \\
\hline Female & $11(9.3)$ & \\
\hline \multicolumn{3}{|l|}{ Religion } \\
\hline Christian & $70(59.4)$ & \multirow{3}{*}{0.018} \\
\hline Moslem & $24(20.3)$ & \\
\hline Traditionalist & $24(20.3)$ & \\
\hline \multicolumn{3}{|l|}{ Age } \\
\hline$<18$ yrs & $2(1.7)$ & \multirow{4}{*}{0.270} \\
\hline $18-25$ yrs & $47(39.8)$ & \\
\hline $26-30 \mathrm{yrs}$ & $36(30.5)$ & \\
\hline $30-55$ yrs & $33(28.0)$ & \\
\hline \multicolumn{3}{|l|}{ Education } \\
\hline No education & $34(28.8)$ & \multirow{3}{*}{0.046} \\
\hline Basic level & $40(33.9)$ & \\
\hline At least 2nd cycle level & $44(37.3)$ & \\
\hline \multicolumn{3}{|l|}{ Marital status } \\
\hline Single & $66(55.9)$ & \multirow{2}{*}{0.069} \\
\hline Married & $52(44.1)$ & \\
\hline \multicolumn{3}{|l|}{ Occupation } \\
\hline Unemployed & 47 (39.9) & \multirow{3}{*}{0.003} \\
\hline Self-employed & $68(57.6)$ & \\
\hline Government worker & $3(2.5)$ & \\
\hline
\end{tabular}

euphoria and enhance sexual prowess [26]. The respondents habitually remain in the practice for various psychological and physical gratifications which include euphoria, attentiveness, high energy levels, pain relief, and improved sexual performance [27]. However, some of the actions and inactions of the youth in Ghana are attributed to the associated benefits of tramadol abuse. The Food and Drug Authority (FDA) admits that there has been reported incidence of addiction, armed robbery, youth vandalism, car accidents, and, in some cases, violence which were linked to the influence of unapproved intake of tramadol by perpetrators [28]. In addition, Delase of FDA remarked that people especially respondents take tramadol for extra energy for manual workers, euphoria (tramadol can produce euphoria comparable to heroin even at a single dose of $75 \mathrm{mg}$ ), and staying alert for long hours, especially for commercial vehicle drivers and their mate(s) and students, making them dazed and easily drift to deep restful sleep were some of the related benefits for the abuse of tramadol among the respondents [28]. Whereas majority of tramadol users do not intend to take the drug for a prolonged period of time, the therapeutic effects together with the feelings of euphoria and decreased anxiety often lead a user to take more than prescribed, for a longer period than originally intended (often without the prescribing physician's knowledge) [22]. It indeed a reality that tramadol has been 
TABLE 7: Other factors associated with tramadol abuse.

\begin{tabular}{|c|c|c|c|}
\hline \multirow{2}{*}{ Reasons for tramadol abuse } & \multicolumn{2}{|c|}{ Variable category $(N=152)$} & \multirow{2}{*}{$p$ value } \\
\hline & Yes $n / N(\%)$ & No $n / N(\%)$ & \\
\hline History of any other substance abuse & $133(77.6)$ & $19(22.4)$ & $p<0.001$ \\
\hline Relieve pain & $136(89.5)$ & $16(10.5)$ & 0.530 \\
\hline Increase personal euphoria & $102(84.1)$ & $50(15.9)$ & 0.046 \\
\hline Relieve stress/frustration & $98(64.5)$ & $54(35.5)$ & 0.235 \\
\hline Increase physical performance & $119(62.5)$ & $33(37.5)$ & 0.216 \\
\hline Improve sexual performance & $86(56.6)$ & $66(43.4)$ & 0.001 \\
\hline Enhance sleep & $58(38.2)$ & $94(61.8)$ & 0.696 \\
\hline Boost appetite & $51(33.6)$ & $101(66.4)$ & 0.160 \\
\hline Relieve of frustration & $70(46.5)$ & $82(53.5)$ & 0.069 \\
\hline Become courageous/brave & $79(52.0)$ & $73(48.0)$ & 0.153 \\
\hline High perception level on benefits & $96(63.2)$ & $56(36.8)$ & 0.027 \\
\hline Knowledge on dangers/consequences & $53(34.9)$ & $99(65.1)$ & 0.009 \\
\hline Bad parental influence & $70(46.1)$ & $82(52.9)$ & 0.894 \\
\hline Peer influence & $127(83.6)$ & $27(16.4)$ & 0.625 \\
\hline Curiosity & $129(84.9)$ & $25(15.1)$ & 0.642 \\
\hline Easy accessible/not properly regulated & $93(61.2)$ & $59(38.8)$ & 0.380 \\
\hline Poor parental control & $83(54.6)$ & $69(45.4)$ & 0.179 \\
\hline Posttraumatic/pain management dependence & $58(38.2)$ & $94(61.8)$ & 0.044 \\
\hline Over-the-counter drug patronage & $77(50.7)$ & $75(49.3)$ & 0.931 \\
\hline Know a person taking tramadol without a physician prescription & $113(74.3)$ & $39(25.7)$ & 0.001 \\
\hline Have at least a single reason & $120(78.9)$ & $32(21.1)$ & 0.001 \\
\hline
\end{tabular}

TABle 8: Determinants of tramadol abuse/misuse among the respondents.

\begin{tabular}{|c|c|c|c|}
\hline Variables & $p$ value & Odds ratio & $95 \% \mathrm{CI}$ \\
\hline \multicolumn{4}{|l|}{$\begin{array}{l}\text { History of other substance } \\
\text { abuse }\end{array}$} \\
\hline Abuse & 0.009 & 5.149 & $1.501-17.656$ \\
\hline No abuse & \multicolumn{2}{|c|}{${ }^{*}$ Reference } & \\
\hline \multicolumn{4}{|l|}{ Sexual enhancement } \\
\hline Yes & 0.011 & 3.776 & $1.352-10.545$ \\
\hline No & \multicolumn{2}{|c|}{ *Reference } & \\
\hline \multicolumn{4}{|l|}{ Occupation } \\
\hline Unemployed & 0.011 & 0.100 & $0.017-0.595$ \\
\hline Self-employed & 0.058 & 0.200 & $0.038-1.055$ \\
\hline Government workers & \multicolumn{2}{|c|}{${ }^{*}$ Reference } & \\
\hline \multicolumn{4}{|l|}{$\begin{array}{l}\text { Posttraumatic/pain } \\
\text { treatment dependence }\end{array}$} \\
\hline Yes & 0.004 & 0.237 & 0088-0.640 \\
\hline No & \multicolumn{2}{|c|}{ Reference } & \\
\hline
\end{tabular}

${ }^{*}$ No. of users $=152$; CI: confidence interval; ref: reference category; Omnibus test $\left(\chi^{2}=38.885\right.$ and $\left.p=000\right)$ and Hosmer and Lemeshow test $(p=0.315)$.

found to significantly improve sexual satisfaction and delayed ejaculation [29]. There is widespread evidence with its ability in reuptaking of norepinephrine and serotonin in the body but delays in ejaculation is unclear [29]. A significant positive association was found between having inade- quate knowledge on adverse effects and tramadol abuse. There is relatedness and consistency with the study findings in Gaza in 2013 [23]. Also, a study on adolescence abuse of the drug revealed the limited knowledge of participants on the consequences of the tramadol abuse [30]. Lastly, a significantly positive association between posttraumatic/pain management and tramadol abuse was observed. This observation is similar to the finding of a study conducted in Northern Ghana [27].

4.4. Predictors of Tramadol Abuse. The main findings indicated that the history of abuse of other substances, sexual enhancement, postdependence from trauma/pain management, and occupation were associated negatively with the respondents abusing tramadol. This is consistent with a study conducted in the Western Region of Ghana [8]. A study conducted in Sweden affirmed the link between the use of tramadol as aphrodisiac and been tested positive for tramadol [31]. Also, the role of postpain/traumatic dependence on the abuse of tramadol was elucidated in a critical review report [32].

Despite the addiction potential of this drug coupled with the adverse effects, the veracity of its use in the management of trauma and patients in severest pains cannot be underestimated [33]. The findings from the municipality alone with its unique culture and the inherit constraint of the study design might limit the generalizability of our findings.

In view of the study outcomes, further larger and longitudinal studies are proposed. More biochemical analyses are 
needed especially the constituents of the emerging substances that attract the respondents. We will recommend more vigorous investigation on substance use patterns and the physical and psychiatric comorbidity among the respondents using these substances including prescription-only opioids like tramadol.

\section{Conclusion}

The findings of the study revealed that, among the respondents in the municipality, $77.6 \%$ of the tramadol users are inappropriately taking or misusing/abusing the drug. In fact, history of abuse of other substances, sexual enhancement, postdependence from trauma/pain management, and occupation were the independent predictors of the tramadol abuse. Also, there is a looming danger since majority of the respondents are indulged in the abuse of other substances and drugs like codeine, alcohol, and snuff/sera. The trend of the insurgence of abuse of emerging substances like the smoking of dried faeces and drinking of soaked diapers/used pads is a worrisome situation and a wake-up call to stakeholders especially the law-enforcement authorities within the municipality.

\section{Abbreviations \\ UNODC: United Nation Office of Drugs and Crime \\ CYPD6: Cytochorome P450 2 D6 \\ SMHT: Submunicipal Health Team \\ ENA: Essential Nutrition Action \\ AOR: Attributable odds ratio \\ CI: $\quad$ Confidence interval \\ WHO: World Health Organization \\ USA: $\quad$ United State of America \\ GNCB: Ghana Narcotics Control Board \\ KAP: $\quad$ Knowledge, attitude, and practice.}

\section{Data Availability}

Relevant data has been added in the manuscript from which all logical conclusions were driven. Do not hesitate to contact the corresponding author for the dataset.

\section{Ethical Approval}

The scientific review committee of Research and Development Division of Ghana Health Service approved the study protocol.

\section{Consent}

The participated respondents were asked to duly sign a consent form after obtaining the informed concern from them during the administration of the instrument. The purpose of the study was explained to them. Respondents were assured of confidentiality of their information, and they were also made to understand that participation was voluntarily and respondents could opt out at any stage of the study.

\section{Conflicts of Interest}

All authors declare that they have no conflict of interests.

\section{Authors' Contributions}

Saapiire Ferguson and Namillah Godfrey conceived, planned, and designed the study. Saapiire Ferguson and Namillah Godfrey analyzed the data. Saapiire Ferguson, Tanye Vincent, and Abdulai Abubakari drafted and wrote the manuscript. All authors contributed to the data interpretation and critical revision of the manuscript and read and approved the final manuscript.

\section{Acknowledgments}

The authors wish to thank their research assistants Justine, Daniel, and Solomon for their committed work. Our sincerest thanks go to Ghana Health Service (the regional director, district directors, and submunicipal in-charges) and the community leaders for the permission to carry out the present study. Our last appreciation goes to the tutors and principal of the St. Joseph Nursing Training College, Jirapa, for the encouragement and polishing the entire research process.

\section{References}

[1] United Nation Office on Drugs and Crime, Drugs and Age :Drugs and Associated Issues among Young People and OlderWorld drug report, United Nations publication, Sales No. E.18.XI.9, 2018.

[2] United Nations Office on Drugs and Crime, "World Drug Report 2019," in Word Drug Report - 2019 Stimulants, United Nations publication, 2019, Sales No. E.19.XI.8.

[3] S. Derakhshan and R. Boostani, Tramadol induced seizure: a 3year study. April, 2-5, Caspian Journal of Internal Medicine, 2012.

[4] United Nations Office on Drugs and Crime, Substance Abuse Treatment and Care for Women : Case Studies and Lessons Learned, United Nations publication, Sales No. E.04.XI.24, 2004, ISBN 92-1-148194-5.

[5] A. A. Adenugba and F. B. Okeshola, "Substance abuse among females in Nigeria," International Journal of Business and Social Science, vol. 9, no. 5, pp. 99-105, 2018.

[6] National Council of State Boards of Nursing, "Substance Use Disorder in Nursing," National Council of State Boards of Nursing, 2011, https://www.ncsbn.org/SUDN_11.pdf.

[7] P. S. Kumah, Tramadol Usage Soar in Upper West Region, Ghanaweb, 2018.

[8] E. Elliason, B. Sandow, S. Kpangkpari, and R. Asiaktiwen, "Abuse and misuse of tramadol among the respondents in the Wassa Amenfi west municipality in the Western region of Ghana," Psychology \& Psychological Research International Journal, vol. 2018, no. 7, p. 3, 2018.

[9] N. Hassan, "Tramadol has become a household for the Respondents of Kpandai District," 2018, https://www .modernghana.com/news/832181/tramadol-has-become-ahousehold-for-the-respondents-of.html.

[10] J. Jeffrey, "Morphine Addiction and Abuse - Opiate Painkiller Addiction," 2019, https://www.addictioncenter.com/opiates/ morphine/. 
[11] M. Elhabiby, Non-medical Use of Synthetic Opiods Highlighting Tramadol, Ain Sham University, 2018.

[12] D. M. Bush, Emergency department visits for adverse reactions involving the insomnia medication Zolpidem, The CBHSQ Report, 2013, http://www.ncbi.nlm.nih.gov/pubmed/ 27606404.

[13] World Health Organisation, Tramadol, Update Review Report, World Health Organization, 2014, http://www.who.int/ medicines/areas/quality_safety/6_1_Update.pdf.

[14] E. Aryee, "Akpeteshie, Wee mixture patronage rises in Sunyani," 2015, https://www.ghanaweb.com/ GhanaHomePage/NewsArchive/Akpeteshie-Wee-mixturepatronage-rises-in-Sunyani-383275.

[15] S. Lord and L. Marsch, "Emerging trends and innovations in the identification and management of drug use among adolescents and young adults," Adolescent Medicine: State of the Art Reviews, vol. 22, no. 3, pp. 649-xiv, 2011.

[16] GNCB, 2020, Respondents Smoke Dried 'Poo-Poo' for Energy AYV Newspaper News -Sierra Leone News, AYV Sierra Leone, Wake Up Sierra Leone, AYV News, Sierra Leone News, Leone News. Respondents Smoke Dried 'Poo-Poo' for Energy AYV Newspaper News -Sierra Leone News, AYV Sierra Leone, Wake Up Sierra Leone, AYV News, Sierra Leone News, Leone News.html.

[17] A. F. Granville-Garcia, M. A. Clementino, M. . N. C. Gomes, R. T. Firmino, G. L. A. Ribeiro, and M. B. L. D. Siqueira, "Alcohol consumption among adolescents:," Ciência \& Saúde Coletiva, vol. 19, no. 1, pp. 7-16, 2014.

[18] D. C. Husaini and R. Mann, “Adolescents' perception of harms, benefits and intention to use marijuana within the context of regulatory changes in Belize," Texto e Contexto Enfermagem, vol. 28, no. spe, pp. 1-14, 2019.

[19] C. N. Coffie, "Prevalence of substance use among junior high school pupils of the Dangme West District. August, 95," 2010, http://ugspace.ug.edu.gh.

[20] E. A. Mensah, "Substance use among students of a second cycle institution in Accra," 2016, http://ugspace.ug.edu.gh.

[21] S. Sreedharan, M. P. Kamath, U. Khadilkar et al., "Effect of snuff on nasal mucosa," American Journal of Otolaryngology - Head and Neck Medicine and Surgery, vol. 26, no. 3, pp. 151-156, 2005.

[22] P. J. Anzaku, The critical assessment of knowledge, attitude and prevalence of drug abuse among adults and teenagers in Surulere local government area (L.G.A), Lagos state, Nigeria; a case study of tramadol, Tecana American University Education, 2019.

[23] R. Mohammed, H. Jehad, and A. A. Abed, Assessment of tramadol abuse among clients who are attending private psychiatric clinics -KAP study, 2013.

[24] A. W. Ibrahim, M. M. Yerima, S. K. Pindar et al., "Tramadol abuse among patients attending an addiction Clinic in North-Eastern Nigeria : outcome of a four year retrospective study," Advances in Psychology and Neuroscience, vol. 2, no. 2-1, pp. 31-37, 2017.

[25] B. Pourmohammadi and M. A. Jalilvand, "Tramadol abuse and its related factors among higher education students in the city of Damghan, Semnan Province, Iran," Iranian Chemical Communication, vol. 7, pp. 415-423, 2019.

[26] B. Lucia, "Domestic Drug Consumption in Ghana; An underreported phenomenont," July 2019 , http://www .GlobalInitiative.net.
[27] A. G. Fuseini, A. Afizu, Y. H. Yakubu, and G. Nachinab, "Facilitators to the continuous abuse of tramadol among the youth: a qualitative study in northern Ghana," Nursing Open, vol. 6, no. 4, pp. 1388-1398, 2019.

[28] J. A. Okertchiri, "Ghana's Fight against Tramadol Abuse," GhanaWeb: Opinions of Saturda, 2018, https://www .ghanaweb.com/GhanaHomePage/features/Ghana-s-fightagainst-tramadol-abuse-649148.

[29] A. H. Khan and D. Rasaily, "Tramadol use in premature ejaculation: daily versus sporadic treatment," Indian Journal of Psychological Medicine, vol. 35, no. 3, pp. 256-259, 2013.

[30] M. M. Bassiony, G. M. Salah El-Deen, U. Yousef et al., “Adolescent tramadol use and abuse in Egypt," American Journal of Drug and Alcohol Abuse, vol. 41, no. 3, pp. 206-211, 2015.

[31] M. O. Olsson, A. Öjehagen, L. Brådvik, R. Kronstrand, and A. Håkansson, High rates of tramadol use among treatmentseeking adolescents in Malmö, Sweden : a study of hair analysis of nonmedical prescription opioid use. 2017, Journal of Addiction, 2017.

[32] WHO, Critical Review Report : Tramadol. November, 12-16, World Health Organization, 2018.

[33] American Addition Center, "A Guide to Tramadol Abuse and Addiction," 2019, https://www.rehabs.com/tramadol-abuseand-addiction/. 